\title{
Blood glucose and serum insulin responses to breakfast including guar gum and cooked or uncooked milk in Type 2 (non-insulin-dependent) diabetic patients
}

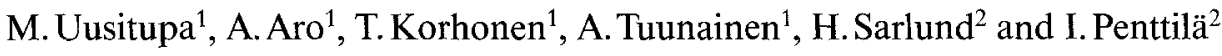 \\ Departments of ${ }^{1}$ Medicine, and ${ }^{2}$ Clinical Chemistry, University of Kuopio, Kuopio, Finland
}

\begin{abstract}
Summary. The post-prandial blood glucose and serum insulin responses to test meals, each including $300 \mathrm{ml}$ fat-free milk taken separately with the meal or premixed before cooking into the meal consisting of oatmeal porridge, were studied in 10 diet-treated Type 2 (non-insulin-dependent) diabetic subjects. The modifying effect of guar gum on the responses was also studied by supplementing both types of test meals with $5 \mathrm{~g}$ granulated guar gum taken at the beginning of the meal. The blood glucose response was higher after the meal which contained cooked milk than after the respective meal with
\end{abstract}

milk taken separately. The guar gum supplementation attenuated the blood glucose response after the meals, but the effect was more pronounced after the meal containing cooked milk. Post-prandial serum insulin responses were similar after all test meals. The results suggest that cooking may facilitate the absorption of lactose from milk-containing foods, and that supplementation with guar gum may counteract this response.

Key words: Blood glucose, serum insulin, milk, breakfast, guar gum, Type 2 diabetes.
It has been commonly accepted that dietary lactose exerts a fast action on blood glucose concentration. Therefore, in dietary recommendations for diabetic subjects the consumption of milk has been restricted to $600 \mathrm{ml}$ of fat-free milk daily [1]. However, a recent study has suggested that lactose causes a smaller increase in blood glucose than does the same amount of glucose [2].

To find the best way of administering milk to diabetic patients, we studied the effects of milk taken separately with a meal or premixed into a meal prepared by cooking, in diet-treated Type 2 diabetic patients. We also studied the effects of guar gum supplementation of the milk-containing meals on the post-prandial blood glucose and serum insulin responses.

\section{Material and methods}

\section{Subjects}

Ten diet-treated Type 2 diabetic patients (seven men, three women, aged $40-63$ years) were studied. The diagnosis of diabetes was confirmed according to the recommendations of WHO Expert Committee on Diabetes Mellitus [3]. In one patient disturbed glucose tolerance had, however, apparently become normal after dietary therapy. The duration of clinical diabetes ranged from 1 to 7 years (mean 3.9 years). The mean \pm SD fasting blood glucose level was $7.74 \pm$ $1.75 \mathrm{mmol} / \mathrm{l}$. Seven of the patients were $>10 \%$ overweight (Metropolitan Life Insurance Tables data). Informed consent was obtained from each subject before the beginning of the study. Approval for the study was given by the Ethical Committee of the University of Kuopio.

\section{Experimental design}

After an overnight fast the subjects consumed the following test meals as breakfast, in random order at intervals of 1 week. Test meal 1: oatmeal porridge cooked in $300 \mathrm{ml}$ water, accompanied by $300 \mathrm{ml}$ fatfree milk and $100 \mathrm{ml}$ non-caloric soft drink. Test meal 2: oatmeal porridge cooked in $300 \mathrm{ml}$ fat-free milk, $300 \mathrm{ml}$ water and $100 \mathrm{ml}$ non-caloric soft drink. Test meal 3: test meal 1 supplemented with $5 \mathrm{~g}$ granulated guar gum (Guarem, Remeda Pharmaceuticals, Kuopio, Finland) mixed with non-caloric soft drink and ingested at the start of the meal. Test meal 4: test meal 2 supplemented with $5 \mathrm{~g}$ guar gum as described above.

The oatmeal porridge was prepared of $40 \mathrm{~g}$ rolled oats, $300 \mathrm{ml}$ fatfree milk or water, $10 \mathrm{~g}$ butter and $2 \mathrm{~g}$ table salt. The rolled oats were mixed into boiling water or milk, and the porridge was cooked for $10 \mathrm{~min}$ at a standard temperature $\left(80^{\circ}-85^{\circ} \mathrm{C}\right)$. All test meals were identical in volume and caloric content yielding $325 \mathrm{kcal}(1360 \mathrm{~kJ})$; $50 \%$ carbohydrates, $31 \%$ fat and $19 \%$ proteins. Each meal was consumed within $5 \mathrm{~min}$.

\section{Methods}

Venous blood samples were obtained before the meals (fasting sample) and 15, 30, 60, 90, and 120 min after the meals. From the samples blood glucose was determined by a glucose oxidase method (Glox, Kabi, Stockholm, Sweden) and serum insulin by radioimmunoassay (antiserum M 8309, Novo, Bagsvaerd, Denmark). The sensitivity of the method was $2 \mathrm{mU} / 1$ and the coefficient of variation $5.4 \%$. 

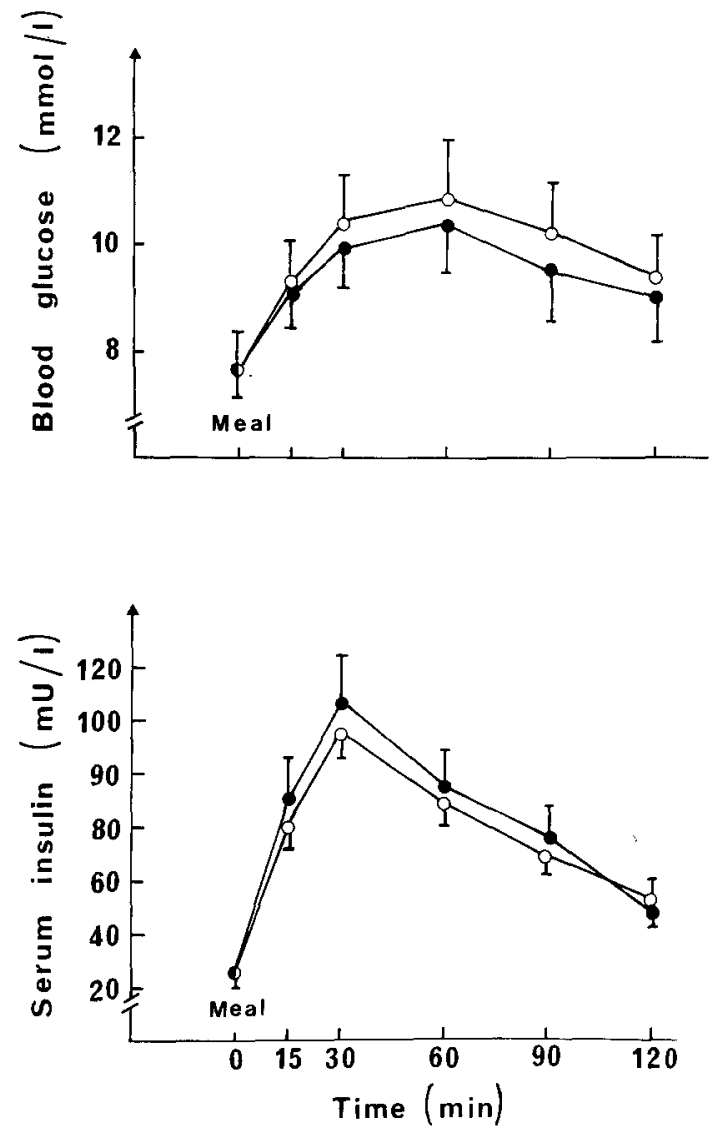

Fig. 1. Blood glucose and serum insulin responses to the test meal 1 (- ; separately taken milk) and $2(\mathrm{O}-\mathrm{O}$, premixed and cooked milk). The difference between post-prandial blood glucose responses was statistically significant $(p<0.001$; ANOVA)

\section{Statistical analyses}

Analysis of variance (ANOVA) and two-tailed paired t-test were used in the statistical analyses of the results. The results are given as mean \pm SEM.

\section{Results}

The blood glucose and serum insulin responses to meals 1 and 2 are shown in Figure 1. The blood glucose response was higher after test meal 2 (with cooked milk) than after test meal 1 (with uncooked milk taken separately; $p<0.001$, ANOVA). However, no significant differences were found in the mean post-prandial blood glucose levels at any individual time point. The sum of post-prandial blood glucose values was $50.0 \pm$ $4.6 \mathrm{mmol} / 1$ after meal 2 and $47.8 \pm 4.0 \mathrm{mmol} / 1$ after meal 1 . The respective serum insulin levels after the two meals were equal.

Figure 2 shows the effect of guar gum supplementation on the blood glucose and serum insulin responses. The blood glucose response after meal 4 was significantly lower than after the corresponding meal without guar gum (meal $2 ; p<0.001$, ANOVA). There was also a
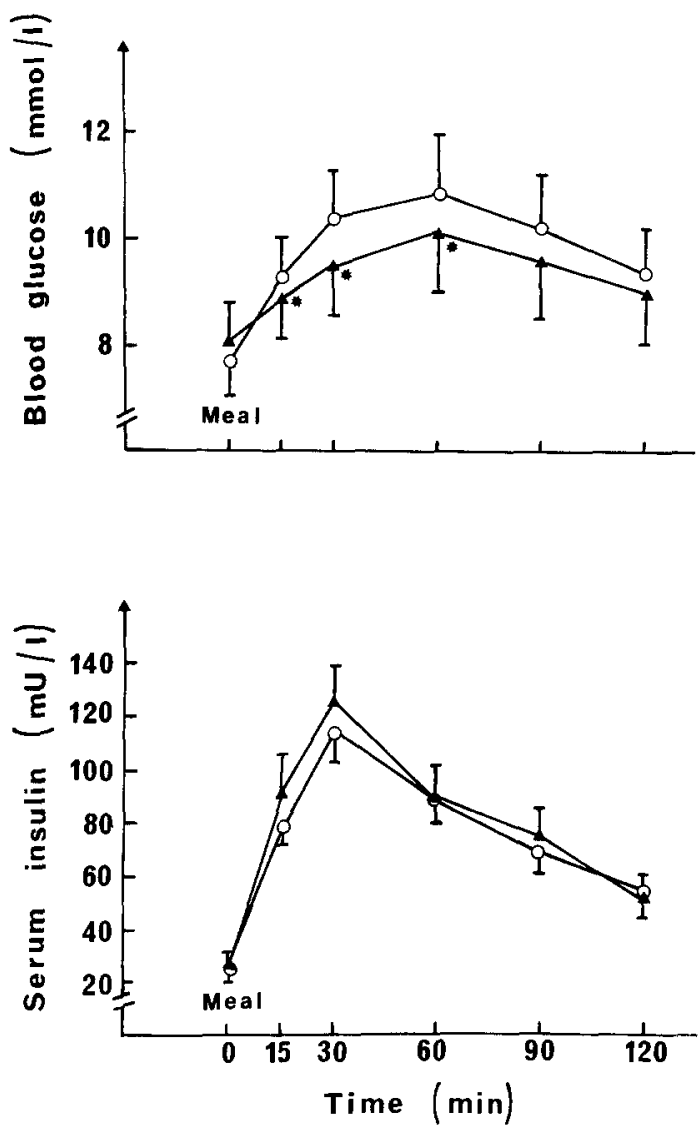

Fig. 2. Blood glucose and serum insulin responses to the test meals 2 $(\mathrm{O}-\mathrm{O}$; premixed and cooked milk without guar gum) and 4 ( $\Delta$; same with guar gum). The difference between post-prandial blood glucose responses was statistically significant $(p<0.001$; ANOVA). $* p<0.05$; paired t-test

significant difference in the mean blood glucose levels at 15,30 , and $60 \mathrm{~min}(p<0.05$; paired t-test). The sum of post-prandial blood glucose values was $46.9 \pm$ $4.8 \mathrm{mmol} / 1$ after meal 4 , as compared with $50.0 \pm$ $4.6 \mathrm{mmol} / 1$ after meal $2(p<0.05)$. However, no difference was observed in the respective serum insulin levels. The blood glucose response after test meal 3 also remained lower than after test meal 1 ( $p<0.01$; ANOVA), but no differences were found in the respective insulin responses (Fig.3). The sum of post-prandial blood glucose values after meal 3 was $46.2 \pm 5.0 \mathrm{mmol} / 1$.

\section{Discussion}

The results showed that the post-prandial blood glucose response resulting from the ingestion of meal 2 was higher than that from meal 1 . There were two differences between meals 1 and 2. Firstly, in meal 2 the milk was mixed with the ingredients before cooking, and secondly, the premixed milk in meal 2 was cooked in contrast to the separately consumed milk in meal 1 . The mixing of milk into the porridge could hardly explain the observed difference. In fact, one would expect an 

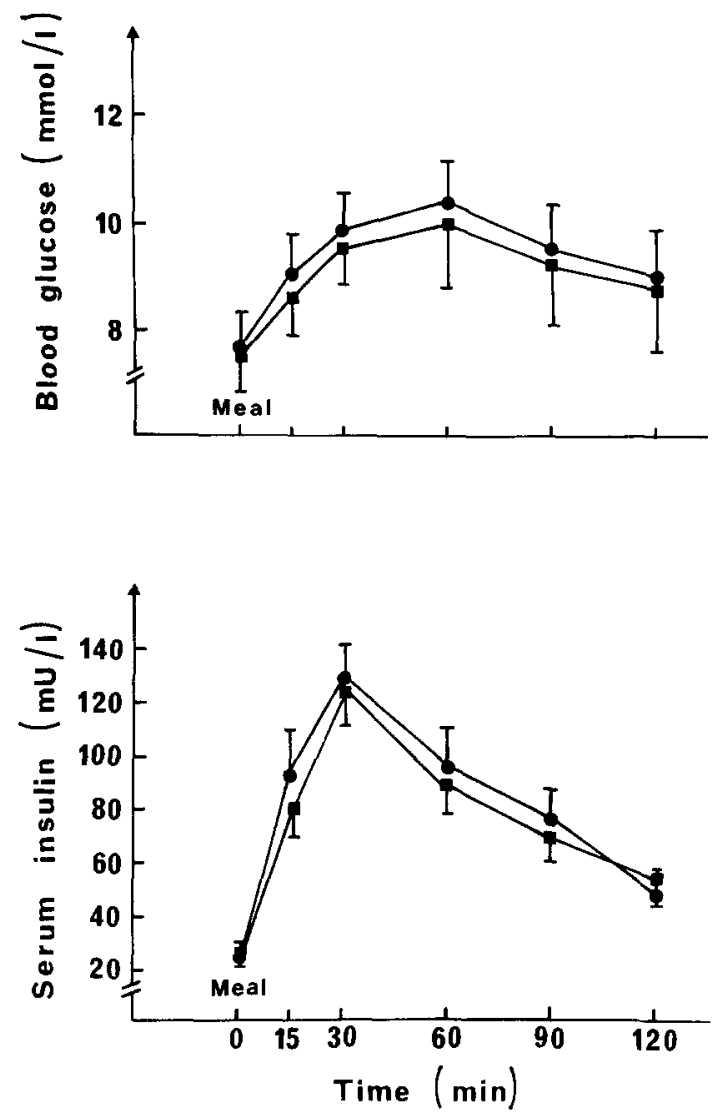

Fig.3. Blood glucose and serum insulin responses to the test meal 1 ( separately taken milk with guar gum). The difference between postprandial blood glucose responses was statistically significant $(p<$ 0.01 ; ANOVA)

opposite effect exerted by the fibre content of rolled oats and by the possible formation of poorly available carbohydrate-protein complexes [4]. It thus seems probable that the cooking of milk was responsible for the enhanced glycaemic response after meal 2.

Glucose causes a greater increment in blood glucose than does the same amount of lactose [2]. Heating is capable of increasing the hydrolysis of lactose into glucose and galactose [4], and this may explain the higher response which was observed after cooked milk. Cooking has also a splitting or gelatinizing effect on starch, making it more easily available for enzymatic hydrolysis $[5,6]$. However, this does not explain the present results, because the starch in the oatmeal porridge was cooked in a similar way in all test meals.

In accordance with the results of previous studies [7], dietary supplementation with guar gum attenuated the blood glucose responses to the test meals. The effect was more pronounced in the meal which contained premixed, cooked milk. In fact, the guar gum supplementation abolished the difference which was observed be- tween meals 1 and 2. Evidently, the fibre was capable of retarding the absorption of the monosaccharides formed during cooking more effectively than it affected the lactose from the separately ingested milk.

There was no difference between the serum insulin responses to the different test meals. In some studies where large amounts of gel-forming fibre have been given to people, reduced plasma insulin levels have been observed after fibre-supplemented meals [7]. The relatively small dose of fibre which was used in the present study might explain the lack of difference in insulin responses. Similarly, we found no alteration in plasma insulin response by guar gum supplementation in Type 2 diabetic patients who were treated with oral hypoglycaemic agents [8].

In conclusion, the present findings suggest that cooking of milk may facilitate the absorption of lactose from milk-containing foods. They also suggest that the resulting higher blood glucose responses might be counteracted by dietary supplementation with guar gum.

Acknowledgements. This work was supported by the Foundation for Nutrition Research, Helsinki, Finland.

\section{References}

1. Huttunen JK, Aro A, Pelkonen R, Puomio M, Siltanen I, Åkerblom HK (1982) Dietary therapy in diabetes mellitus. Acta Med Scand 211: $469-475$

2. Ionescu-Tirgoviste C, Popa E, Sintu E, Mihalache N, Cheta D, Mincu I (1983) Blood glucose and plasma insulin responses to various carbohydrates in Type 2 (non-insulin-dependent) diabetes. Diabetologia 24: $80-84$

3. WHO Expert Committee on Diabetes Mellitus (1980) Second report, Technical Report Series, No 646. Geneva

4. Nickerson TA (1978) Lactose. In: Webb BH, Johnson AH, Alfort JA (eds) Fundamentals of dairy chemistry, 2nd edn. AVI Publishing, Westport, pp 273-324

5. Collings P, Williams C, McDonald J (1981) Effects of cooking on serum glucose and insulin responses to starch. $\mathrm{Br}$ Med J 282: 1032

6. Snow P, O'Dea K (1981) Factors affecting the rate of hydrolysis of starch in food. Am J Clin Nutr 34: 2721-2727

7. Jenkins DJA (1979) Dietary fibre, diabetes and hyperlipidaemia. Progress and prospects. Lancet 2: 1287-1290

8. Aro A, Uusitupa M, Voutilainen E, Hersio K, Korhonen T, Siitonen O (1981) Improved diabetic control and hypocholesterolaemic effect induced by long-term dietary supplementation with guar gum in Type 2 (insulin-independent) diabetes. Diabetologia 21: $29-33$

Received: 22 September 1983

and in revised form: 6 April 1984

Dr. Matti Uusitupa

Department of Medicine

University of Kuopio

SF-70210 Kuopio 21

Finland 